\title{
Anotaciones básicas sobre la Administración Local de Castilla y León
}

\author{
Miguel Domínguez-Berrueta de Juan \\ Catedrático de Derecho Administrativo \\ Universidad de Salamanca
}

\begin{abstract}
Sumario: I. INTRODUCCIÓN. II. LAS RELACIONES ENTRE LA COMUNIDAD AUTÓNOMA Y LAS ENTIDADES LOCALES Y LAS COMPETENCIAS LOCALES DE LA COMUNIDAD AUTÓNOMA DE CASTILLA Y LEÓN. 2.1. Las relaciones entre la Comunidad Autónoma de Castilla y León y las Entidades locales. 2.2. Las competencias de la Comunidad Autónoma de Castilla y León en materia local. III. LA ADMINISTRACIÓN LOCAL DE CASTILLA Y LEÓN: PERSPECTIVA GENERAL. IV. LA ORGANIZACIÓN PROVINCIAL DE CASTILLA Y LEÓN. V. LA REGULACIÓN AUTONÓMICA DEL MUNICIPIO. 5.1. El término municipal. Creación y supresión de municipios y alteración de sus términos. 5.2. Las competencias municipales. 5.3. Nombre, capitalidad y símbolos del Municipio. VI. ENTIDADES SUPRAMUNICIPALES. 6.1. La comarca en Castilla y León. La Ley de comarcalización del Bierzo. 6.2. Mancomunidades. 6.3. Otras entidades asociativas. VII. ENTIDADES LOCALES MENORES. VIII. LA DIFÍCIL PROBLEMÁTICA DEL CONDADO DE TREVIÑO. IX. EL PACTO LOCAL. LA SEGUNDA DESCENTRALIZACIÓN ADMINISTRATIVA.
\end{abstract}

\section{INTRODUCCIÓN}

Pocas materias hay tan polémicas, si es que hay alguna, en nuestro ordenamiento jurídico como la organización territorial. Sin duda son los temas autonómicos, y en especial, no nos engañemos, los referidos a determinadas Comunidades Autónomas, los que han centrado las discusiones políticas y sociales durante los últimos años. Sin embargo, junto a dichas cuestiones, dotadas de tan marcada trascendencia mediática, conviven otros, no de menor importancia, que han caído quizás en un cierto descuido por parte de los medios.

Uno de esos temas es el de la Administración local, elemento central de nuestra organización administrativa, en cuanto sigue siendo la instancia más próxima al ciudadano, con todo lo que eso conlleva ${ }^{1}$. Lo que obliga a que el análisis de sus problemas y sus vicisitudes es y deba ser uno de los elementos primarios de la ciencia jurídica.

La doctrina iuspublicista ha tenido, en este sentido, mayor juicio que los grandes medios de comunicación social, y no se ha dejado seducir por los

\footnotetext{
${ }^{1}$ Como señala la Carta Europea de Autonomía Local, de 15 de octubre de 1985, en su preámbulo, es a nivel local donde el derecho de los ciudadanos a participar en la gestión de los asuntos públicos «puede ser ejercido más directamente». A lo que añade que «la existencia de Entidades locales investidas de competencias efectivas permite una administración más eficaz y próxima al ciudadano».
} 
temas de moda autonómicos, y se ha mantenido fiel, como no podía ser de otro modo, a la ya rancia tradición jurídica, de desbrozar los asuntos locales, como lo que son, uno de los grandes temas del Derecho administrativo.

En absoluto ajena a este logro, es la labor ingente desarrollada durante su ya prolongada historia por la Revista de Estudios de Administración Local y Autonómica, que alcanza en este momento su número 300, para satisfacción de todos aquellos que hemos sido, a lo largo de nuestra carrera, lectores asiduos, y en ocasiones honrados colaboradores, de sus páginas. Es, por ello, un motivo de satisfacción colaborar, con ocasión de dicho acontecimiento, con un estudio sobre un tema, entendemos, adecuado al efecto, como lo es el estudio de la Administración Local de nuestra, en muchas ocasiones olvidada, Comunidad de Castilla y León.

A nuestra Comunidad Autónoma le costó ciertamente ver la luz. Cuando la Constitución de 1978 reconoció, en su art. 2 «la autonomía de las nacionalidades y regiones que la integran», trastocando, como en tantas otras cosas, las estructuras jurídicas y políticas preexistentes, Castilla y León se vio cogida, en cierto modo, a contra paso ${ }^{2}$.

La conversión en un ente autonómico de un territorio carente en esa fecha de reseñables pretensiones autonomistas, en las que la totalidad de su población se consideraba, y se sigue considerando, más español que castellano leonés ${ }^{3}$, debía ser necesariamente difícil.

Así lo fue en la práctica, provocando la existencia de serias dificultades para consolidar un territorio autonómico y, lo que resultó aún más laborioso, una verdadera conciencia regional. El tiempo, sin embargo, ha ido curando esas heridas, y hoy en día la Comunidad de Castilla y León, camina hacia su consolidación, y comienza a tener cada vez más una marcada conciencia de si misma.

La persistencia de algunos problemas al respecto, marcadamente el supuesto aún no cerrado del Condado de Treviño, al que más tarde nos referiremos, no puede empañar ese logro, que ha permitido centrar la problemática territorial en temas más útiles para la satisfacción de los intereses de los ciudadanos, como lo es la búsqueda de una adecuada organización municipal, que permita una correcta prestación de los servicios públicos.

\footnotetext{
${ }^{2}$ Leguina Villa, J., Escritos sobre autonomías territoriales. Tecnos. Madrid, 1995. Segunda edición, p. 125.

${ }^{3}$ Como señala J. L. Martínez LóPEZ-MuÑIZ, «Castilla y León está compuesta por provincias, ciudades, villas y pueblos, de fuerte personalidad histórica, que sienten y viven intensamente su existencia plural y diversa, y a su vez su indiscutible unidad geográfica, económica, cultural, histórica, étnica y política en la realidad de los dos antiguos reinos fundidos desde hace siglos, y en la superior comunidad de la nación española». «Descentralización local en Castilla y León», en Descentralización y Administración local. Coordinador: J. L. Martínez López-Muñiz, p. 84.
} 
No es nuestra Comunidad un territorio carente de serias dificultades en este ámbito, pues la existencia de una notable asimetría en las estructuras locales de la Comunidad, a la que se añade la presencia de un elevado número de municipios con una más que reducida población, que determina, a su vez, una marcada carencia de los medios personales y materiales para hacer frente al ejercicio de las funciones básicas encargadas a la Administración municipal, obstaculiza bastante el logro de este objetivo.

Se ha señalado, por ello, al respecto, que el «cuadro de las estructuras de la Administración Local de la región resulta (...) notablemente asimétrico, más allá de la formalidad de los consabidos escalones de rango constitucional: Provincias y Municipios. La asimetría es especialmente importante en el tamaño y capacidad de los Municipios, aunque todos tengan la misma estructura organizativa básica y similares competencias. Pero la asimetría práctica tampoco es desdeñable entre la realidad de las nueve Provincias, como consecuencia precisamente de la asimetría municipal en la que las Provincias se enraizan, e incluso del diverso número de partidos judiciales de cada una de ellas» ${ }^{4}$.

Rivero Ortega advirtió, por ello, del riesgo de que «poco a poco los municipios pierdan competencias o sean incapaces de ejercitarlas, subrogándose la Comunidad Autónoma en su ejercicio, hasta que la despoblación del territorio acabe con cientos de municipios protegidos firmemente por la "garantía institucional"» 5 .

La propia Exposición de Motivos de la Ley de Régimen Local de Castilla y León ha puesto de manifiesto este problema, señalando que «no puede olvidarse que Castilla y León es una Comunidad con una población de derecho algo superior a 2.500 .000 habitantes que se distribuye de forma muy desigual a lo largo de su geografía. Esta población que representa aproximadamente el 6,5\% de la total del Estado se distribuye en 2.247 municipios que, a su vez, representan el 27, $8 \%$ del total de municipios de la nación. Por otra parte, del total de municipios en la Comunidad Autónoma sólo 47 -2, 09 \% del total disponen de una población de derecho superior a los 5.000 habitantes y el 86,27 $\%$ cuenta con menos de 1.000 habitantes de los cuales 1051 no superan los 250 . Los anteriores datos son reveladores de la grave situación municipal en la Comunidad, que se manifiesta, fundamentalmente a través del gran número de municipios existentes, su dispersión geográfica, y, demográficamente, de escaso tamaño, así como en clara regresión económica y administrativa.

Este declive de una densa y dilatada historia municipal ha convertido a Castilla y León, en el ámbito rural, en un amplio territorio despoblado en el que más que asentarse sobreviven minúsculos núcleos de población con un

\footnotetext{
${ }^{4}$ Propuesta del Gobierno Autonómico para la consecución del Acuerdo de Pacto Local de Castilla y León, p. 43.

5 Rivero Ortega, R., «Autonomía local y competencias: Castilla y León en el escenario previo al pacto local», en Revista de Estudios de la Administración Local 286-287 (2001), p. 132.
} 
gradual proceso de disminución y envejecimiento. La mayoría de estos núcleos, aunque conservan su condición de municipios, son incapaces, por carecer de medios personales y materiales, de autogobernar sus intereses, resultando inviables desde la perspectiva de una satisfacción racional y moderna de sus propias necesidades colectivas que constituye la justificación formal y material de su existencia institucional.

En resumen, la amplitud de competencias frente a la escasez de recursos, hace estéril el principio constitucional de autonomía municipal al no contar muchas Entidades Locales con otros medios financieros que las ayudas de otras Administraciones Públicas. Esta realidad conduce a la necesidad de un marco normativo que facilite, promueva y fomente la integración de los municipios inviables en otros de población, territorio y riqueza suficiente para el cumplimiento de sus fines y que, por otra parte, regule las actuaciones planificadas para la consecución de una estructura municipal racional, cuando la iniciativa local falle o el localismo injustificado frustre soluciones racionales de integración. La supresión de municipios se contempla en la Ley, pues, con una especial atención «en el caso de estructuras material y organizativamente inviables».

\section{LAS RELACIONES ENTRE LA COMUNIDAD AUTÓNOMA Y LAS ENTIDADES LOCALES Y LAS COMPETENCIAS LOCALES DE LA COMUNIDAD AUTÓNOMA DE CASTILLA Y LEÓN}

\subsection{Las relaciones entre la Comunidad Autónoma de Castilla y León y las Entidades locales}

La entrada en escena de las Comunidades Autónomas, supone la introducción de un nuevo nivel administrativo, que asume un papel intermedio entre el Estado y las Entidades Locales, lo que implica que éstas quedan obligadas a relacionarse con un nuevo foco de poder, que va a asumir, en consecuencia, competencias respecto a ellas ${ }^{6}$. Resultado ineludible de dicho factor es la necesidad de introducir cambios, que vengan a dar respuesta a la nueva situación derivada de la consolidación del Estado autonómico ${ }^{7}$.

\footnotetext{
${ }^{6}$ Como señala R. Barranco Vela, la «existencia de Comunidades Autónomas, implica también la confirmación de un nivel intermedio de poder político entre el nivel local y el estatal. De ello se deriva necesariamente que, dada la estrecha conexión que en todos esos niveles se da entre los diversos intereses públicos, el poder local no se va a relacionar exclusivamente con el estatal, ni sus competencias van a depender tan sólo de las determinaciones estatales. Autonomía local y autonomía regional aparecen así como la expresión de dos intereses en parte coincidentes, pero que también pueden colisionar parcialmente». Creación y segregación de municipios. Marcial Pons. Madrid, 1993, p. 111.

7 Como señala J. L. MeILÁn GiL, resulta «evidente la necesidad de introducir algún cambio en las estructuras tradicionales de las Administraciones local y estatal, cuando entre el nivel nacional y el local
} 
El Tribunal Constitucional ha sentado, en tal sentido, el carácter bifronte de las Entidades Locales, en cuanto éstas no constituyen un mero elemento de la Administración autonómica, sino que son al mismo tiempo que tales, elemento de división y organización del territorio del Estado, por lo que se van a situar en una situación de dependencia no sólo respecto a la Administración autonómica, sino también respecto a la estatal (STC 84/1982, de 23 de diciembre) ${ }^{8}$.

A partir de aquí, sin embargo, no se ha dado una respuesta al grado de vinculación en que se debe situar la Administración local en relación con cada uno de estos poderes. Algunos se sitúan claramente en la órbita de incluir lo local bajo el manto de poder autonómico, dando un marcado protagonismo a los Estatutos de Autonomía a la hora de concretar las competencias locales (FONT i LlOVET) ${ }^{9}$. Frente a ello, otros se muestran contrarios a esta concepción, considerando que una interpretación como la anterior acabaría conduciendo a una suerte de "Administración única", en la que no quedaría espacio para una verdadera descentralización, que permitiese la configuración de un gobierno local vigoroso y eficaz. Destacando, en consecuencia, el lugar propio que corresponde a la Administración local, y la imposibilidad de reducirlo a una mera parte de la Administración de la Comunidad Autónoma (ORTEGA) ${ }^{10}$.

aparece la Comunidad Autónoma. Parece una exigencia de sentido común: todo no puede quedar igual». «Autonomías y descentralización», en Descentralización y Administración Local. Coordinador: J. L. Martínez López-Muñiz, p. 28. 8 Más concretamente, señala el Tribunal Constitucional que el «carácter bifronte del régimen jurídico
de las administraciones locales (...), no es contradictorio con la naturaleza que a las entidades locales
atribuye la Constitución, cuyo art. 137 concibe a municipios y provincias como elementos de división
y organización del territorio del Estado. Dividido y organizado también éste, en su integridad y sin
mengua de ellas, en Comunidades Autónomas, ambas formas de organización se superponen sin anu-
larse, y si bien el grado superior de autonomía, que es el propio de las Comunidades, les otorga poten-
cialmente, un poder político y administrativo sobre los municipios y provincias que se incluyen en su
territorio, éstas y aquéllos no desaparecen, ni se convierten en meras divisiones territoriales para el
cumplimiento de los fines de la Comunidad, aunque puedan cumplir también esta función. Las provin-
cias siguen siendo (...) divisiones territoriales para el cumplimiento de actividad del Estado, y munici-
pios y provincias, como entes dotados de personalidad jurídica propia (...) pueden ser autorizados por
el ordenamiento para asumir a título singular el desempeño de funciones o la gestión de servicios que
el Estado proponga transferirles o delegarles y que se corresponden con su ámbito de intereses propios,
definido por la Ley». STC $84 / 1982$, de 23 de diciembre. FJ. 4 . Ésta misma idea ha sido destacada en
la doctrina por L. MoREL OcANa, que señala que la «Constitución contempla las instituciones locales
como parte integrante de la organización territorial del Estado. (...) Pero, al mismo tiempo, reconoce la
profunda vinculación que existe entre aquellas instituciones y las Comunidades Autónomas». A lo que
añade, posteriormente, que el «Régimen local es, pues, parte integrante de la organización del Estado
y, además, es un componente de la estructura interna de la correspondiente Comunidad Autónoma». La
Administración local. Tecnos. Madrid, 1984, pp. 145 y 148.

9 En tal sentido, T. Font i Llovet, que considera que «en nuestro ordenamiento existe un verdadero "déficit estatutario" en la regulación del régimen local, y que sólo el Estatuto es el tipo normativo adecuado para determinar con garantía los elementos definidores de la autonomía local, debido a que es la única norma capaz de imponerse al mismo tiempo al legislador estatal y autonómico». «El régimen local en la reforma de los Estatutos de Autonomía», en El régimen local en la reforma de los Estatutos de Autonomía. Centro de Estudios Políticos y Constitucionales. Madrid, 2006, p. 14.

${ }^{10}$ En tal sentido, L. ORTEGA considera que «si el modelo actual sufriese una interiorización autonómica, se haría en una situación funcional de espacios competenciales mínimos donde la voluntad autonó- 
La LRLCyL ${ }^{11}$ fija el marco general en el que deben desarrollarse las relaciones entre la Comunidad Autónoma y las Entidades Locales, tomando pie en las ideas de colaboración y cooperación ${ }^{12}$, en los propios términos de la ley, unas y otras ajustarán sus relaciones recíprocas «a los deberes de lealtad e información mutua, colaboración, coordinación, respeto a los ámbitos competenciales respectivos y ponderación de los intereses públicos implicados, cualquiera que sea la Administración que los tenga a su cargo» (art. 81).

Este marco trata de ser plenamente respetuoso con la autonomía local, a la vez que pretende dar cumplimiento al principio de subsidiariedad, que otorga el desarrollo de las funciones públicas a la instancia más próxima al ciudadano, siempre que sea adecuada para desarrollarlas.

En lo que se refiere al respeto a la autonomía local, constitucionalmente consagrada, como es de sobra conocido, en el art. $137 \mathrm{CE}$, que otorga a municipios y provincias «autonomía para la gestión de sus respectivos intereses», encuentra claro reconocimiento en el art. 83. 1 LRLCyL, según el cual la «Comunidad Autónoma, en el marco de las competencias que tenga asumidas, y a través de las leyes reguladoras de los distintos sectores de la acción pública, atribuirá a los municipios y provincias las competencias que su derecho a la autonomía demanda».

En cuanto al principio de subsidiariedad, con alcance general aparece claramente consagrado en el art. 4. 3 CEAL, que establece que el «ejercicio de las competencias públicas debe, de modo general incumbir preferentemente a las autoridades más cercanas a los ciudadanos. La atribución de una competencia a otra autoridad debe tener en cuenta la amplitud o la naturaleza de la tarea o las necesidades de eficacia o economía».

mica de constituirse en la "Administración única" limitaría una descentralización local. No se interiorizaría una Administración local potente y vigorosa en un modelo de gestión basada en la subsidiariedad, sino una Administración local de la que se sigue desconfiando como ente político y de gestión alternativo al propio poder autonómico». A lo que añade que «los entes locales no forman parte del ordenamiento jurídico autonómico, sino que lo local se constituye como un ordenamiento propio relacionado con el estatal y el autonómico bajo el principio constitucional de autonomía». «En tal sentido, cada ordenamiento local tiene su propia colectividad política, distinta de la autonómica, con capacidad de expresión política diferenciada para la elección de su propia organización y la adopción de las decisiones de consulta popular que consienta la legislación». «La interiorización autonómica del régimen local», en en El régimen local en la reforma de los Estatutos de Autonomía. Centro de Estudios Políticos y Constitucionales. Madrid, 2006, pp. 55-56.

${ }^{11}$ Sobre dicha ley puede consultarse, Rivero OrTEgA, R., «Régimen local de Castilla y León: estudio de la Ley 1/1998, de 4 de junio», en Revista de Estudios de Administración Local y Autonómica 277 (1998).

12 Señala M. T. CARballeira Rivera que «el debate sobre la vertebración del poder público no fluye ya sobre un discurso de la autonomía en clave de separación-garantía sino de colaboración-integración, aspectos ambos que coexisten en nuestro actual orden constitucionalizado. La autonomía no es en este caso una "defensa de" sino una garantía de "participación en" que da lugar a una nueva definición relacional subrayada por el dialogo en el momento decisorio y la mediación de las instancias locales con las instancias superiores en la fase dinámica de actuación. No se trata ya de un problema de definición del poder que le es reconocido a los entes como de racionalizar los modos y procedimientos a través de los cuales pueden ejercitarse óptimamente esos poderes». La provincia en el sistema autonómico español. Marcial Pons. Madrid, 1993, p. 18. 
Nuestra legislación autonómica de régimen local es sensible a dicho postulado, como muestra el art. 83. 2 LRLCyL, que establece que las «funciones y competencias de la Comunidad Autónoma en las que sea preferente el interés de la colectividad local, serán objeto de transferencia a las Entidades Locales, siempre que se garantice una más eficaz prestación de servicios»; y en el art. 83. 3 LRLCyL, que señala que podrán «ser objeto de delegación en las Entidades Locales las funciones y competencias de la Comunidad Autónoma, cuando se mejore la eficacia de la gestión pública y se alcance una mayor participación ciudadana» ${ }^{13}$.

\subsection{Las competencias de la Comunidad Autónoma de Castilla y León en materia local}

Sentada la doble vinculación de la Administración local al Estado, por un lado, y a las Comunidades Autónomas, por otro, se hace preciso determinar el conjunto de competencias que va a corresponder a cada una de estas instancias respecto a las Entidades Locales.

Hay que partir, al respecto, de la conocida partición constitucional entre dos tipos de Comunidades Autónomas: las que acceden a la autonomía por alguna de las, en ocasiones, denominadas vías rápidas, y las que acceden por la denominada vía lenta. Como es sabido, las segundas podían asumir únicamente aquellas competencias que aparecían recogidas en el listado del art. 148 CE. Tan sólo, transcurridos cinco años, y mediante la reforma de sus Estatutos, las Comunidades Autónomas podían ampliar sucesivamente sus competencias dentro del marco establecido en el art. 149 CE (art. 148. $2 \mathrm{CE}$ ). Frente a ello, las Comunidades de vía rápida, no tenían necesidad de esperar ese periodo de cinco años, sino que desde un primer momento podían asumir competencias dentro del marco del ya citado art. $149 \mathrm{CE}$ (art. $151 \mathrm{CE})$.

Nuestra Comunidad, engarzada dentro de aquellas que alcanzaron la autonomía por la vía ordinaria tenía, por tanto, como techo competencial, en un primer momento, el conjunto de competencias a las que se refería el art. $148 \mathrm{CE}$. En lo que hace referencia al ámbito local, al que nos estamos refiriendo, esto suponía que las Comunidades Autónomas podían asumir competencias respecto a las «alteraciones de los términos municipales comprendidos en su territorio y, en general, las funciones que correspondan a la

\footnotetext{
${ }^{13}$ Esa transferencia y delegación de competencias podrá realizarse a favor de: a) Diputaciones Provinciales; b) Municipios con población superior a 5000 habitantes; c) Municipios que cuenten con servicios culturales, educativos, sanitarios, sociales, administrativos o de otra naturaleza mediante los cuales se satisfaga la demanda de los residentes en otros municipios limítrofes, siempre que tengan capacidad de gestión; d) Comarcas; e) Mancomunidades, comunidades de villa y tierra y áreas metropolitanas (art. 84. 1 LRLCyL).
} 
Administración del Estado sobre las Corporaciones locales y cuya transferencia autorice la legislación sobre Régimen Local» (art. 148. $\left.12^{\circ} \mathrm{CE}\right)^{14}$.

Trascurrido el plazo de cinco años al que hacía referencia el art. 148. 2 CE, sin embargo, se hizo posible la asunción de competencias por la Comunidad de Castilla y León, con los límites fijados en el art. 149 CE, esto es, siempre que no se tratara de materias reservadas al Estado por dicho precepto. No contempla la Constitución expresamente, sin embargo, la Administración local como un ámbito de competencia estatal, pero si implícitamente, pues del art. 149. 1. 18 de la Constitución se deriva necesariamente que son competencia estatal las bases de la Administración local.

Esa ampliación competencial no se llevó a efecto por la reforma estatutaria de 1994, sino por la de 1999, realizada por la Ley Orgánica 4/1999, de 8 de enero, en la que se atribuyen ya a la Comunidad Autónoma todas las competencias para el desarrollo y la ejecución en materia de régimen local, sin restricciones ${ }^{15}$.

Más en concreto, es el art. 34. 1 del Estatuto de Autonomía de Castilla y León ${ }^{16}$ quien asume dicha función, al establecer que, en «el marco de la legislación básica del Estado y, en su caso, en los términos que ella establezca, es competencia de la Comunidad de Castilla y León el desarrollo legislativo y la ejecución de la legislación del Estado en las siguientes materias: (...)

\section{$3^{\circ}$. Régimen Local».}

Los procedimientos para llevar a efecto la transferencia o delegación se iniciarán de oficio por la Comunidad Autónoma, por propia iniciativa o a petición razonada de cualquiera de las Entidades Locales interesadas. Siendo requisito imprescindible para que se inicien tales procedimientos que las funciones objeto de transferencia o delegación se ejecuten íntegramente en la circunscripción de la Entidad Local (art. 84. 2 LRLCyL).

Cuando se trate de transferencia o delegación de competencias a favor de las Diputaciones Provinciales, se realizará conjuntamente para todas ellas. Salvo que la naturaleza o características del servicio exijan que se limite a la Diputación Provincial afectada (art. 85 LRLCyL). Supuesto para el cual el art. 85. 2 LRLCyL, establece alguna peculiaridad.

La regulación detallada de la transferencia se haya recogida en los art. 86 a 90 LRLCyL; y la delegación en los art. 91 a 94 LRLCyL.

${ }^{14}$ Señala Morell OCAÑa que, con ello, la Constitución otorga a las Comunidades Autónomas «un poder de definición de las estructuras locales que quede de acuerdo con las exigencias que en cada una de ellas impone la variedad ecológica, la historia, etc. En suma, la definición de un modo de ser de las instituciones locales acorde con la realidad social y ecológica subyacente». La Administración..., p. 149.

15 Propuesta del Gobierno..., p. 29. De este modo, como añade este mismo documento, en su página 30, la «Comunidad es, pues, competente para legislar sobre la Administración Local de su territorio, dentro de lo dispuesto por la legislación básica estatal, así como para el ejercicio de las competencias de ejecución, incluida la potestad reglamentaria, la inspección, etc. que pudieran legítimamente ser ejercidas sobre ella, en cuanto lo permita la autonomía que tiene constitucionalmente garantizada y lo requiera la legislación básica y autonómica de aplicación».

${ }^{16}$ Ley Orgánica 4/1983, de 25 de febrero, del Estatuto de Autonomía de Castilla y León. 
Dicha tarea ha sido llevada a efecto a través de la Ley 1/1998, de 4 de junio, de Régimen Local de Castilla y León que, como establece en su propia exposición de motivos, tiene «por objeto no solamente establecer un desarrollo legislativo respetuoso con las reglas básicas, sino que pretende ser un complemento de éstas de cara a conseguir un ordenamiento local integrado que facilite su aplicación a los diversos agentes que intervienen en ella y sirva, al propio tiempo, para la necesaria y deseada racionalización de las Administraciones Públicas Locales».

\section{LA ADMINISTRACIÓN LOCAL DE CASTILLA Y LEÓN: PERSPECTIVA GENERAL}

Nuestro ordenamiento jurídico ha consolidado una estructura territorial ciertamente compleja, en la que se superponen hasta seis niveles distintos de entidades administrativas (la Administración Estatal, la Autonómica, la Provincial, la Supramunicipal, la Municipal y la Inframunicipal). En lo que a nosotros interesa, que es el ámbito local, confluyen hasta cuatro escalones administrativos diferentes, todos los cuales han encontrado reflejo en el ordenamiento jurídico de Castilla y León ${ }^{17}$.

En primer lugar, se han consagrado, como no podía ser de otra manera, los dos tipos de Administración local necesaria, cuya existencia y autonomía viene impuesta constitucionalmente: los municipios (art. $140 \mathrm{CE}^{18}$ ) y las provincias (art. $141 \mathrm{CE}^{19}$ ).

El art. 25. 1 EACyL se encarga de la regulación del municipio, señalando que éste «es la entidad local básica de la Comunidad. Goza de personalidad jurídica propia y de plena autonomía para la gestión de sus intereses. Su representación, gobierno y administración corresponde al respectivo ayuntamiento».

\footnotetext{
17 Parada VÁzquez, R., Derecho administrativo II. Organización y empleo público. 14 edición. Marcial Pons, 2000, p. 120. Ballesteros Fernández, A., Introducción al Régimen Local Español. CEMCI. Granada, 1995, p. 27.

${ }^{18}$ Dicho precepto establece que la «Constitución garantiza la autonomía de los municipios. Estos gozarán de personalidad jurídica plena. Su gobierno y administración corresponde a sus respectivos Ayuntamientos, integrados por los Alcaldes y los Concejales. Los Concejales serán elegidos por los vecinos del municipio mediante sufragio universal, igual, libre, directo y secreto, en la forma establecida por la ley. Los Alcaldes serán elegidos por los Concejales o por los vecinos. La ley regulará las condicione en las que proceda el régimen del concejo abierto».
}

${ }^{19}$ Dicho precepto establece que la «provincia es una entidad local con personalidad jurídica propia, determinada por la agrupación de municipios y división territorial para el cumplimiento de las actividades del Estado. Cualquier alteración de los límites provinciales habrá de ser aprobada por las Cortes Generales mediante Ley Orgánica». «El gobierno y la administración autónoma de las provincias estarán encomendados a Diputaciones u otras Corporaciones de carácter representativo». 
A lo que añade el art. 2. 2 LRLCyL que la «Junta de Castilla y León garantizará que los municipios dispongan de los medios adecuados y suficientes para el cumplimiento eficaz de sus fines».

Por su parte, el art. 25. 2 EACyL hace referencia a la provincia, señalando que ésta, «como entidad local, tiene personalidad jurídica propia y plena autonomía para la gestión de sus intereses. Su gobierno y administración están encomendados a la respectiva Diputación. Es, asimismo, el ámbito territorial ordinario para el cumplimiento de las actividades de la Comunidad, sin perjuicio de que ésta pueda establecer otros que resulten adecuados».

El art. 5. 1 LRLCyL establece, además, que son «fines básicos de la provincia garantizar la prestación integral y adecuada en el territorio provincial de los servicios de competencia municipal y colaborar en la tarea de coordinación de la Administración Local con la de la de la Comunidad Autónoma y la del Estado».

También tienen cabida en el ordenamiento local de Castilla y León, las entidades supramunicipales, que encuentran también base constitucional en el art. 141. 3, que si bien no ordena su establecimiento, si contempla la posibilidad de su creación, señalando que se «podrán crear agrupaciones de municipios diferentes a la provincia».

Esta mención supone, en primer lugar, la habilitación para la entrada en nuestra organización administrativa de las comarcas que, aunque no se encuentran expresamente mencionadas en nuestra Norma Fundamental, están implícitamente comprendidas dentro de las agrupaciones mencionadas en el art. $141.3 \mathrm{CE}^{20}$.

En nuestra Comunidad Autónoma dichas figuras han encontrado plasmación en el art. 25. 3 EACyL, que permite mediante una ley de las Cortes de Castilla y León, específica para cada supuesto, la creación de Comarcas, mediante la agrupación de municipios limítrofes, atendiendo al informe previo de los municipios afectados y sus características comunes».

Las Comarcas tendrán, según establece el art. 6 LRLCyL, como finalidad, gestión conjunta de los intereses o servicios de los municipios que la integran y la colaboración en el ejercicio de sus competencias.

Así como en el art. 25. 4 EACyL, en el que se contempla la posibilidad de regular, mediante Ley de Cortes, la creación y el reconocimiento de Mancomunidades y otras agrupaciones de municipios».

\footnotetext{
${ }^{20}$ Sosa Wagner, F., Manual de Derecho local. Aranzadi. Pamplona. Quinta edición, 2000, p. 126. Como señala J. L. RIVERo YSERN, la comarca ha recibido en nuestro ordenamiento jurídico un reconocimiento «puramente incidental». Manual de Derecho Local. Quinta edición. Civitas. Madrid, 2003, p. 257.
} 
Según el art. 29. 1 LRLCyL son Mancomunidades de municipios «las asociaciones que éstos formen voluntariamente para la ejecución en común de obras y servicios determinados de su competencia. Su ámbito de actuación no podrá extenderse a la totalidad de competencias asignadas a los propios municipios que las integran».

A lo que añade el art. 29. 2 LRLCyL que tienen la «condición de Entidad Local, personalidad y capacidad jurídica para el cumplimiento de sus fines específicos». Este mismo precepto aclara que se regirán por lo establecido en sus propios Estatutos, siempre en el respeto de lo dispuesto en la LRLCyL.

Por último, el art. 25. 3 EACyL contempla también la posibilidad de que por Ley de Cortes, y en el marco de la legislación básica del Estado, se regulen las Entidades Locales Menores y otras formas tradicionales de organización municipal.

El art. 49. 1 LRLCyL aclara que son Entidades Locales Menores aquellas entidades de ámbito territorial inferior al municipio que bajo diversas denominaciones tienen reconocido dicho carácter y las que en lo sucesivo se creen con arreglo al procedimiento previsto en la propia LRLCyL.

Dichas entidades «tendrán la consideración de Entidad Local, personalidad y capacidad jurídica plena para el ejercicio de sus competencias» (art. 49. 2 LRLCyL).

\section{LA ORGANIZACIÓN PROVINCIAL DE CASTILLA Y LEÓN}

Como ya habíamos apuntado previamente la delimitación de los límites geográficos de Castilla y León fue un proceso sumamente difícil, que encontró numerosos obstáculos ${ }^{21}$.

El origen de nuestra Comunidad hay que buscarlo en la creación del ente preautonómico, mediante Real Decreto-Ley de 13 de junio de $1978^{22}$, que extendía la preautonomía de Castilla y León a las provincias de Ávila, Burgos, León, Logroño, Palencia, Salamanca, Santander, Segovia, Soria, Valladolid y Zamora.

De este listado se caerían, sin embargo, tanto Logroño como Santander, que abandonaron el marco Castellano leonés para constituirse, como es de

\footnotetext{
${ }^{21}$ Bilbao Ubillos, J. M., «Disposiciones generales del Estatuto y elementos constitutivos de la Comunidad», en Derecho Público de Castilla y León. Valladolid, 1999, pp. 42-43.

${ }^{22}$ Real Decreto-Ley de 13 de junio de 1978, num. 20/78, Consejo General de Castilla y León. Creación.
} 
sobra conocido en Comunidades Autónomas uniprovinciales, con base en lo dispuesto en el art. 143. $1 \mathrm{CE}$, según el cual «las provincias con entidad regional histórica podrán acceder a su autogobierno y constituirse en Comunidades Autónomas».

No ha habido una valoración uniforme de dicha decisión, que fue acertada para algunos ${ }^{23}$; y poco justificable, en opinión de otros ${ }^{24}$. Pero lo cierto es que su segregación del territorio autonómico se llevó a la práctica, quedando como único vestigio de su inicial inclusión en Castilla y León, una cláusula en la DT $7^{25}$, que prevé una improbable reincorporación de dichos territorios a la Comunidad ${ }^{26}$.

No gozaron, sin embargo, de este poder de decisión ni León, ni Segovia. Ambas provincias intentaron también salir de la Comunidad castellanoleonesa, para transformarse en Comunidades uniprovinciales. Una y otra tentativa se vieron abocadas al fracaso.

En el caso de León, el propio Tribunal Constitucional cerró las puertas a dicha posibilidad, mediante Sentencia de 28 de septiembre de $1984{ }^{27}$, que algunos sectores aceptaron sólo a regañadientes, en cuanto siguen defendiendo la entidad regional de esta provincia ${ }^{28}$.

\section{LA REGULACIÓN AUTONÓMICA DEL MUNICIPIO}

\subsection{El término municipal. Creación y supresión de municipios y alteración de sus términos}

Una vez definido con carácter general la figura del municipio como entidad local básica de la organización territorial de la Comunidad, en los términos que vimos en su momento, la LRLCyL se enfrenta a la regulación de

\footnotetext{
${ }^{23}$ De Esteban, J.; González-Trevijano, P., Curso de Derecho Constitucional Español III. Madrid, 1994, p. 791.

${ }^{24}$ Ruipérez Alamillo, J., Formación y determinación de las Comunidades Autónomas en el ordenamiento constitucional español. Tecnos. Madrid, 1998, p. 63.

${ }^{25}$ Establece dicho precepto que, en «caso de que una Comunidad Autónoma decida, a través de sus legítimos representantes, su disolución para integrar su territorio en el de la Comunidad Autónoma de Castilla y León, la incorporación deberá ser aprobada por las Cortes de Castilla y León o por el Pleno del Consejo General a que se refiere la Disposición transitoria primera».

${ }^{26}$ Así lo consideraron, entonces, Domínguez-Berrueta de Juan, M.: Fernando Pablo, M. F.; SánCHEZ FERnÁndeZ DE GATTA, D., «Apuntes sobre el proceso de formación de la Comunidad Autónoma de Castilla y León: organización básica de la Comunidad», en Relaciones Sociolaborales. Aspectos jurídicos, económicos y sociales. J. Ortega Esteban (Ed.). Ediciones Universidad de Salamanca. Salamanca, 1993, p. 420

${ }^{27}$ STC 89/1984, de 28 de septiembre.

28 Véase al respecto, Bilbao Ubillos, Disposiciones generales..., p. 44.
} 
su territorio, afirmando que el «término municipal es el territorio en el que el Ayuntamiento ejerce sus competencias». A lo que añade que éste será continuo, sin perjuicio de las discontinuidades reconocidas actualmente (art. 3. 1 LRLCyL).

La división del término municipal en distritos y barrios y sus variaciones es competencia exclusiva del Ayuntamiento, sin perjuicio de la obligación de éste de dar conocimiento a la Comunidad de Castilla y León (art. 4. 1 LRLCyL).

La LRLCyL se encarga también de regular la creación, supresión y alteración de los términos del municipio. Fijando una regla común, que será aplicable a todos estos supuestos, según la cual todo municipio pertenecerá a una sola provincia, sin que cualquier alteración de los términos municipales pueda modificar los limites provinciales (art. 4. 2 LRLCyL). A dicha norma se añade una regulación específica de cada uno de estas tres figuras, creación, supresión y alteración, y del procedimiento común que debe seguirse para llevarlas a efecto. Todo recogido en el Título II de la LRLCyL.

En primer lugar la Ley se refiere a la creación de municipios, que podrá tener lugar por la segregación de parte del territorio de otro u otros limítrofes o por la fusión de éstos (art. 9 LRLCyL). El primer supuesto se llevará a cabo con sujeción a los requisitos contenidos en el art. 10 LRLCyL ${ }^{29}$; mientras que el segundo se podrá acordar cuando se de alguna de las causas que establece el art. 11. 1 LRLCyL ${ }^{30}$, comportando la supresión de los municipios afectados (art. 11. 2 LCLCyL) y teniendo en cuenta la voluntad de los municipios afectados (art. 12. 2 LRLCyL).

El art. 12 LRLCyL regula la supresión de municipios, que podrá tener lugar por la incorporación de uno o más municipios a otro u otros limítrofes, cuando se de alguna de las causas que recoge el art. 13 LRLCyL ${ }^{31}$, o por la fusión

\footnotetext{
${ }^{29}$ Concretamente exige cuatro requisitos de carácter positivo y dos de carácter negativo. Los de carácter positivo son: a) que existan motivos permanentes de interés público; b) que el núcleo o núcleos a segregar cuenten con una población mínima de mil residentes; c) que cuente con un territorio y recursos suficientes para el adecuado cumplimiento de las competencias y servicios municipales. En cuanto a los requisitos negativos, se pide: a) que dicha creación no suponga una privación de las condiciones expresadas en los apartados anteriores; b) que no implique una disminución para su población del nivel o calidad de los servicios que se le venían prestando (art. 10 LRLCyL).

${ }^{30}$ Concretamente se podrá acordar siempre que concurra cualquiera de las siguientes causas: a) cuando separadamente carezcan de capacidad o recursos suficientes para atender los servicios mínimos exigidos por la Ley; b) cuando sus núcleos de población se confundan como consecuencia del desarrollo urbanístico; cuando existan notorios motivos demográficos, económicos, administrativos o de cualquier otro carácter que pudieran hacerla necesaria o conveniente (art. 11. 1 LRLCyL).

${ }^{31}$ Concretamente, se podrá acordar por la concurrencia de alguna de las siguientes causas: a) falta de población o descenso acusado y progresivo de la misma; b) confusión de sus núcleos de población con otro u otros como consecuencia del desarrollo urbanístico; c) insuficiencia de medios para prestar los servicios mínimos exigidos por la Ley; d) falta reiterada de candidatos en las elecciones de sus órganos de gobierno o la falta de funcionamiento de los mismos; e) existencia de condiciones económicas, administrativas o de cualquier otro carácter que pudieran hacerla necesaria o conveniente.
} 
de dos o más municipios limítrofes, como ya vimos. En ambos casos se deberá tener en cuenta la voluntad de los municipios afectados (art. 12. 2 LRLCyL).

También permite la Ley la alteración parcial de términos municipales, mediante la segregación de parte del territorio de un municipio para agregarlo a otro limítrofe, por alguna de las causas que establece el art. 15. $1 \mathrm{LRLCyL}^{32}$. Si bien dicha segregación no será posible cuando con ella disminuya la calidad o nivel de los servicios que venían recibiendo tanto los vecinos residentes en el municipio del que se segrega una parte del territorio como los vecinos residentes en el municipio al que dicho territorio se agrega. Tampoco será viable la segregación de ningún núcleo de población de un término municipal cuando se halle unido por calle o zona urbana a otro del municipio originario (art. 15. 2 LRLCyL).

Por último, en lo que se refiere al procedimiento, la Ley contiene una regulación mínima, que apenas si alcanza a la iniciación y resolución del mismo. En lo que se refiere a la iniciación se podrá producir de oficio o a instancia de parte (art. 16. 1 LRLCyL). La iniciación de oficio corresponde a la Consejería competente en materia de Administración Local (art. 16. 2 LRLCyL).

La iniciación a instancia de parte puede llevarse a cabo mediante solicitud de los municipios o de las Diputaciones provinciales interesadas, en ambos casos requerirá acuerdo de la Corporación correspondiente aprobado por mayoría absoluta del número legal de miembros de la respectiva Corporación (art. 16. 2 LRLCyL y art. 47. 2 LBRL). También se podrá iniciar por solicitud de la Administración del Estado o de los vecinos interesados. En este último caso, sólo para los supuestos de creación o alteración, y por mayoría de la parte o partes que hayan de segregarse (art. 16. 1 y 16. 4 LRLCyL).

En cuanto a la resolución, que se adoptará en el plazo de nueve meses desde su iniciación por la Junta de Castilla y León ${ }^{33}$, será publicada en el BOCYL, BOE y Boletín de la Provincia, además de darse traslado de la misma a la Administración del Estado (art. 17 LRLCyL).

El título II, culmina con la adopción de un conjunto de medidas dirigidas al fomento de las fusiones e incorporaciones de pequeños municipios ${ }^{34}$. Res-

\footnotetext{
${ }^{32}$ Concretamente, por alguna de las siguientes causas: a) confusión de sus núcleos de población como consecuencia del desarrollo urbanístico; b) necesidad de dotar a un municipio limítrofe del territorio indispensable para ampliar los servicios existentes o instalar aquellos nuevos que imperativamente hubiera de prestar como consecuencia de un aumento de población; c) existencia de condiciones económicas, administrativas o de cualquier otro carácter que pudieran hacerla necesaria o conveniente (art. 15. 1 LRLCyL).

${ }^{33}$ De no dictarse resolución en dicho plazo se entenderá desestimada la petición (art. 17 LRLCyL).

${ }^{34}$ Más concretamente, se fijan un conjunto de medidas para el fomento de las fusiones e incorporaciones de municipios con población inferior a mil residentes: a) se creará un fondo o dotación destinado a
} 
puesta lógica al grave problema existente en nuestra Comunidad en este aspecto ${ }^{35}$, tal y como ya reseñamos. Y con la atribución a la Junta de Castilla y León, a propuesta de la Consejería competente en materia de Administración Local, de la competencia para resolver los conflictos que se susciten entre los municipios acerca del deslinde de sus términos (art. 19. 1 LRLCyL) ${ }^{36}$.

\title{
5.2. Las competencias municipales
}

Otro bloque normativo de la LRLCyL es el dirigido a regular las competencias de los municipios. En él se establece un conjunto de materias en las que éstos ejercerán competencias, en los términos de la legislación del Estado y de las Leyes de la Comunidad Autónoma (art. 20. 1 LRLCyL) ${ }^{37}$. Para lo cual podrán crear y gestionar equipamientos e infraestructuras, planificar su ubicación, programar actividades y prestar cuantos servicios públicos deseen (art. 20. 2 LRLCyL).

\begin{abstract}
acciones directas de fomento y a la concesión de ayudas para una mejor prestación de servicios en los municipios resultantes; b) se fijarán preferencias en su favor y a los mismos fines en los regímenes generales de ayudas a municipios que apruebe la Junta de Castilla y León (teniendo prioridad las comunicaciones entre los núcleos pertenecientes a los municipios fusionados o incorporados y la capitalidad del municipio resultante y aquellas necesidades o servicios derivados directamente de la alteración; c) para facilitar la integración y la eficaz prestación de los servicios municipales, las Diputaciones Provinciales prestarán a los municipios resultantes, asistencia y asesoramiento adecuados y establecerán en su favor, prioridades y preferencias en los Planes Provinciales de Cooperación; d) Se promoverán los convenios y acuerdos oportunos para una eficaz coordinación de las anteriores medidas de fomento con las que pueda establecer el Estado (art. 18 LRLCyL).
\end{abstract}

${ }^{35}$ Muestra clara de esta preocupación de la exposición de motivos del Decreto 7/1985, de 31 de enero, en la que se señala que la «carencia de medios humanos, técnicos y financieros que sufren numerosos municipios de Castilla y León les dificulta enormemente la tarea de prestar a los ciudadanos en ellos residentes los servicios mínimos e incluso de cumplir los más elementales cometidos que el ordenamiento jurídico les atribuye».

${ }^{36}$ En el procedimiento que se siga al efecto se exige informe preceptivo del Instituto Geográfico Nacional y dictamen del Órgano Consultivo Superior de la Comunidad Autónoma, o, en su defecto, del Consejo de Estado (art. 19. 1 LRLCyL). Se deberá dar, además, a las Diputaciones Provinciales, cuando éstas vean afectados sus límites, las mismas posibilidades de participación que se de a los Ayuntamientos de los municipios afectados (art. 19. 3 LRLCyL). Y, en todo caso, se dará audiencia a las Entidades Locales Menores, si se ven afectadas en su delimitación territorial (art. 19. 4 LRLCyL).

${ }^{37}$ Concretamente, en las siguientes materias: a) seguridad en lugares públicos; b) ordenación del tráfico; c) protección civil, prevención y extinción de incendios; d) ordenación, gestión, ejecución y disciplina urbanística; e) parques y jardines, pavimentación y conservación de vías y caminos; f) promoción y gestión de viviendas; g) patrimonio histórico y artístico; h) medio ambiente; gestión de montes y espacios naturales; i) actividades clasificadas; j) defensa de usuarios y consumidores; $\mathrm{k}$ ) equipamientos comerciales, abastecimientos y mataderos; 1) salud pública y sanidad; 11) alumbrado público; m) red de suministro y tratamiento del agua; servicios de limpieza viaria, de recogida y de tratamiento de residuos; n) acción social y servicios sociales; protección de la infancia, atención a la juventud y promoción de la igualdad de la mujer; prevención de la marginalidad e inserción social; ñ) transporte público; o) cultura; p) deportes; q) turismo y tiempo libre; r) colaboración con la administración educativa en la creación, construcción y mantenimiento de centros docentes públicos y en la escolarización; s) cementerios y servicios funerarios; t) cualesquiera otras que se le atribuyan en su ámbito territorial y de gestión (art. 20. 1 LRLCyL). 
A ello añade el art. 21 LRLCyL la obligación de que todos los municipios de Castilla y León presten a sus vecinos los servicios establecidos como mínimos en la legislación básica de régimen local ${ }^{38}$, en condiciones de igual$\mathrm{dad}^{39}$, con independencia del núcleo en el que residan ${ }^{40}$.

La ley permite, no obstante, que se exima de esa obligación a los municipios, a solicitud de sus Ayuntamientos, y previa audiencia a la Diputación Provincial interesada, cuando concurra alguna de las circunstancias que recoge el art. 22. 1 LRLCyL $^{41}$. En la resolución que se adopte dicha dispensa se contendrán las medidas necesarias para que los vecinos afectados por aquélla no queden privados de las prestaciones mínimas; el periodo de duración y efectos de dicha decisión; y el órgano de la Administración que asumirá la prestación del servicios dispensado (art. 23 LRLCyL).

\subsection{Nombre, capitalidad y símbolos del Municipio}

La LRLCyL cierra la regulación del Municipio con un Título dedicado a la regulación de su nombre, capitalidad y símbolos.

Con respecto al nombre, establece que su denominación habrá de ser en lengua castellana, respetándose las denominaciones existentes y sin que pueda ser coincidente o producir confusiones con otras del territorio del Estado (art.

\footnotetext{
38 Téngase en cuenta que el art. 26 LBRL determina cuales son esos servicios distinguiendo según la población municipal. Así, en un primer nivel, todos los municipios deben prestar los servicios de: alumbrado público, cementerio, recogida de residuos, limpieza viaria, abastecimiento domiciliario de agua potable, alcantarillado, acceso a los núcleos de población, pavimentación de las vías públicas y control de alimentos y bebidas. En un segundo nivel se sitúa a los municipios con población superior 5000 habitantes, que además de los anteriores, deberá de prestar los siguientes servicios: parque público, biblioteca pública, mercado y tratamiento de residuos. En un tercer nivel se encuentran los municipios con población superior a 20000 habitantes, que deberán prestar, además, los siguientes servicios: protección civil, prestación de servicios sociales, prevención y extinción de incendios e instalaciones deportivas de uso público. Por último, en los municipios con población superior a 50.000 habitantes, además de los anteriormente citados se deben prestar los siguientes servicios: transporte colectivo urbano de viajeros y protección del medio ambiente.

39 Para lograr esa igualdad, el art. 21. 2 LRLCyL obliga a la Junta de Castilla y León a establecer, previo informe del Consejo de Provincias de la Comunidad de Castilla y León y a propuesta de la Consejería competente en materia de Administración Local, niveles homogéneos de prestación de los servicios mínimos, mediante la fijación de indicadores, resultados o características técnicas de los mismos, según proceda.

${ }^{40}$ Dicho objetivo será objeto de atención preferente para las funciones asistenciales y de cooperación municipal de las Diputaciones Provinciales, así como de la coordinación y ayuda de la Comunidad Autónoma (art. 21. 4 LRLCyL).

${ }^{41}$ En concreto, debe darse alguna de las siguientes circunstancias: a) que por sus características peculiares, resulte imposible o muy difícil el establecimiento o adecuada prestación de dichos servicios por el propio municipio; b) que no sea posible su establecimiento o prestación en breve plazo, aun utilizando procedimientos de asociación con otros municipios o de cooperación con otras Administraciones Públicas; que el esfuerzo fiscal no sea inferior a la media de los municipios de características análogas de la Comunidad Autónoma (art. 22. 1 LRLCyL).
} 
24. 1 LRLCyL). Se prevé, no obstante, un procedimiento para cambiar esa denominación, que requiere para su iniciación acuerdo del Ayuntamiento, adoptado por mayoría absoluta del número legal de miembros de la corporación, que debe ser sometido a información pública e informe de la Diputación Provincial (art. 24. 1 LRLCyL y 47. 2 LBRL). El procedimiento lo resolverá en el plazo máximo de 6 meses la Junta de Castilla y León (art. 25. 3 LRLCyL) ${ }^{42}$.

También se ocupa la Ley de regular el cambio de capitalidad de los Municipios, mediante una remisión al procedimiento establecido en el art. 11 del Texto Refundido de Disposiciones Legales Vigentes en Materia de Régimen Local ${ }^{43}$. Lo que supone que se podrá llevar a efecto por acuerdo la Comunidad Autónoma, previo acuerdo del Ayuntamiento adoptado por mayoría absoluta del número legal de miembros de la corporación e informe de la Diputación Provincial (art. 11 TRDLV y 47. 2 LBRL).

Uno y otro cambio deberán ser comunicados a la Administración del Estado y publicados en el BOE, haciéndose efectivos cuando, tras haber sido anotados en los Registros de las Entidades Locales de la Administración del Estado y de la Comunidad Autónoma, se publiquen en el BOCYL (art. 26 LRLCyL).

Se regula también, por último, la concesión de símbolos, títulos o distinciones a los municipios de Castilla y León, que requerirá un procedimiento en el que será preceptivo la elaboración de una memoria justificativa de la pretensión, acuerdo del Pleno del Ayuntamiento e información pública, y que será resuelta por la Junta de Castilla y León, a propuesta de la Consejería competente en materia de Administración Local, previo los informes que considere necesario o conveniente recabar (art. 27. 2 LRLCyL).

Si bien se permite que los municipios puedan aprobar su propio escudo heráldico o alterar el que los distinga por acuerdo del Ayuntamiento adoptado por mayoría absoluta del número legal de sus miembros, previa instrucción del procedimiento en el que consten las razones que lo justifique, dibujoproyecto del nuevo blasón, e informe del órgano asesor en la materia de la Junta de Castilla y León (art. 28 LRLCyL) ${ }^{44}$.

\footnotetext{
${ }^{42}$ A propuesta de la Consejería competente por razón de la materia, previo informe, según proceda, de la Real Sociedad Geográfica o de la Real Academia de la Historia de y de las Universidades de la Comunidad o de otras instituciones que se consideren oportunas (art. 25. 3 LRLCyL).

${ }^{43}$ Real Decreto Legislativo 781/1986, de 18 de abril, Texto Refundido de las Disposiciones Legales Vigentes en Materia de Régimen Local.

${ }^{44}$ Dicho procedimiento aparece regulado en el Decreto 105/1991, de 9 de mayo, por el que se regula el procedimiento y normas heráldicas de aprobación, modificación y rehabilitación de escudos y banderas municipales.
} 


\section{ENTIDADES SUPRAMUNICIPALES}

\subsection{La comarca en Castilla y León. La Ley de comarcalización del Bierzo}

Ya habíamos visto que la Comarca no aparece expresamente regulada en la Constitución, aunque sí implícitamente reconocida en la misma. De aquí se deriva, como indica RIVERO YSERN, la falta de un pronunciamiento respecto a la competencia y el procedimiento de creación, que remite la cuestión al régimen general de distribución de competencias, del que resulta su atribución a las Comunidades Autónomas, en virtud de su competencia para configurar su propia organización territorial interna y su potestad de autoorganización ${ }^{45}$.

Queda, por ello, a la voluntad de la Comunidad Autónoma la juridificación de una institución que, a pesar de su larga raigambre, no ha tenido tradicionalmente sitio en el mundo legal, manifestándose más bien en otros ámbitos (geográfico, social, político...) ${ }^{46}$.

La incidencia ha sido variable, oscilando desde las Comunidades como Cataluña, en las que esta figura se ha convertido en un elemento esencial de su estructura territorial; hasta las que, como la nuestra, le han dado un reconocimiento limitado. Recientemente, señalaba SÁNCHEZ BLANCO que los «Estatutos de Autonomía han incorporado el concepto de comarca como concreción de las agrupaciones de municipios, con el registro de contenidos diferenciales, que van desde la exigencia de acuerdo favorable de los municipios implicados para llegar a constituir una comarca, requerida por el Estatuto de Andalucía, a la generalización de la comarca en el modelo territorial autonómico de los Estatutos de Cataluña y Asturias, con los puntos intermedios de la simple previsión de creación de comarcas como entidad integrada en la Comunidad Autónoma o como Ente Local» ${ }^{47}$.

Más concretamente, la genérica habilitación para la creación de comarcas se ha traducido únicamente en la creación de la Comarca del Bierzo. Para dar cumplimiento a dicho propósito había que dar cumplimiento de requisitos formales y materiales.

Desde el punto de vista formal era preciso que la aprobación se llevase a cabo mediante una ley de Cortes específica, previo informe de los munici-

\footnotetext{
45 Rivero Ysern (J. L.), Manual de..., pp. 257-258.

46 Sosa Wagner, Manual de..., pp. 125-126. Rivero Ysern, J. L., Manual de..., p. 257. De esta regla general escapa únicamente el caso catalán. Allí ha existido un tradicional rechazo a la organización provincial, considerada una solución artificiosa, impuesta por el centralismo. Esto llevó a que ya en tiempos de la segunda república, se diera reconocimiento legal a la división comarcal del territorio, a través del Estatuto de Autonomía de 1932. Redacción de El Consultor De los Ayuntamientos, Nuevo Régimen Local. Tomo I. El Consultor de los Ayuntamientos y de los Juzgados, 2001, pp. 606-607.
}

47 Sánchez Blanco, A., Organización Intermunicipal. Iustel. Madrid, 2006, p. 77. 
pios afectados (art. 25. 3 EACyL, art. $6 \mathrm{LRLCyL}$ ). Teniendo en cuenta que «no podrá crearse la comarca si a ello se oponen expresamente las dos quintas partes de los Municipios que debieran agruparse en ella, siempre que, en este caso, tales Municipios representen al menos la mitad del censo electoral del territorio correspondiente» (art. 42. 2 LBRL).

Así se hizo en la práctica, mediante la Ley $1 / 1991$, por la que se crea y regula la Comarca del Bierzo ${ }^{48}$, que fue objeto del correspondiente informe previo, sin que ninguno de los municipios afectados se opusiese a la citada comarcalización. Es más, en realidad, se estaba dando con ello satisfacción a una aspiración largamente sentida en dichos municipios.

Desde el punto de vista material, se exigía que los municipios comprendidos fueran limítrofes y estuviesen dotados de unas características comunes (art. 25. 3 EACyL, art. 6 LRLCyL). Requisitos también sobradamente cumplidos, pues, como destaca la propia exposición de motivos de la Ley, la «singularidad de la que la Comarca de El Bierzo aparece revestida, se pone de relieve tanto desde el punto de vista hidrográfico como orográfico. Se dibuja en los $3.000 \mathrm{Km}$. sobre los que se proyecta la Comarca una cadena de estribaciones montañosas que bordean su perímetro, y valles por donde discurren numerosos ríos que nutren la cuenca del Sil, constituyendo de esta manera un marco natural sobre el que se asientan sus 141.000 habitantes. Asimismo, el punto de vista histórico dota de características propias a la Comarca de El Bierzo, pues, aún, dependiendo del antiguo reino de León o del castellanoleonés, según sus vicisitudes. El Bierzo conservó durante decenios el carácter de territorio autónomo al frente del cual un poder señorial tenía la encomienda real de su administración. Incluso once años antes de que Javier de Burgos llevase a cabo la división provincial integrando la Comarca de El Bierzo en la actual provincia de León, aquélla llegó a tener una cierta personalidad administrativa».

La LCB ofrece, en cualquier caso, una regulación no exhaustiva que, en esencia, se limita a regular los aspectos que el art. 42. 3 LBRL obliga a incluir en la Ley Creadora: la determinación del «ámbito territorial de las comarcas, la composición y el funcionamiento de sus órganos de gobierno, que serán representativos de los Ayuntamientos que agrupen, así como las competencias y recursos económicos que, en todo caso, se les asignen».

Así, en su Capítulo I aparece regulado su ámbito territorial, que será, según establece su art. 1, «el delimitado por los términos de los municipios que la integran». Éstos aparecen inicialmente delimitados en este mismo precepto. Concretamente incluye los municipios de Arganza, Balboa, Barjas, Bembibre, Benuza, Berlanga del Bierzo, Borrenes, Cabañas Raras, Carcabelos, Camponaraya, Candín, Carracedelo, Cancedo, Castropomade, Congosto, Corrullón, Cubillos del Sil, Fabero, Folgoso de la Ribera, Igüeña, Molinaseca,

${ }^{48}$ Ley 1/1991, de 14 de marzo, por la que se crea y regula la Comarca del Bierzo. 
Noceda, Oencia, Páramo del Sil, Paranzanes, Ponferrada, Priaranza del Bierzo, Puente de Domingo, Flórez, Sancedo, Sobrado, Toreno, Torre del Bierzo, Trabadelo, Vega de Espinaredad, Vega de Valcarce, Villadecanes y Villafranca del Bierzo. Si bien se añade la posibilidad de que transcurridos los cuatro primeros años de funcionamiento de la Comarca, algún otro municipio limítrofe solicite su incorporación, acordada por el voto favorable de las dos terceras partes del número de hecho y, en todo caso, de la mayoría absoluta del número legal de miembros de la Corporación, que podrá ser aceptado por el Pleno del Consejo Comarcal, previo informe de la Junta de Castilla y León y de la Diputación Provincial de León.

El art. 3 regula las potestades y privilegios de los que disfruta la comarca del Bierzo, reconociéndole todos los que reconoce el art. 4. $1 \mathrm{LBRL}^{49}$ para el ejercicio de sus competencias.

Esas competencias aparecen reguladas en los art. 4 y sigs., que le atribuyen las competencias que le otorguen las leyes sectoriales sobre un conjunto de materias ${ }^{50}$ (art. 4 LCB); la prestación, en todo su ámbito territorial o en una parte del mismo, de los servicios de interés comarcal, complementarios de los municipios y los de competencia municipal cuando su realización o prestación resulte imposible o muy difícil para el Municipio y razones de economía y eficacia así lo aconsejen (art. 5 LCB); las competencias cuya titularidad o ejercicio le transfiera o delegue la Comunidad Autónoma (art. 6 LCB); las que le deleguen los municipios que constituyen la comarca y las que se deriven de los convenios celebrados entre la comarca y esos municipios para la cooperación técnica, económica y administrativa (art. 7 LCB); permite la creación de un servicio de cooperación y asistencia municipales encargado del asesoramiento y asistencia técnica, jurídica y económica a los municipios que, incluidos en su ámbito territorial, lo soliciten (art. 8. 1 LCB); podrá garantizar, si no lo hiciera la Diputación Provincial y, con carácter subsidiario, el ejercicio en las Corporaciones municipales de las funciones públicas de Secretaría, control y fiscalización reservados a los funcionarios con habilitación de carácter nacional (art. 8. 2 LCB); la Diputación Provincial puede transferir, por último, la titularidad o el ejercicio de competencias en materia de Gestión del Plan Provincial de Obras y Servicios dentro del

\footnotetext{
49 Téngase en cuenta que a las Comarcas no le corresponden necesariamente todas las potestades recogidas en el art. 4. 1 LBRL, pues el art. 4. 2 LBRL permite tan sólo que lo dispuesto en ese artículo le sea de aplicación, «debiendo las Leyes de las Comunidades Autónomas concretar cuáles de aquellas potestades serán de aplicación». Por otra parte, el art. 4. 1 LBRL regula las competencias que corresponden en todo caso a los municipios, las provincias y las islas, incluyendo la reglamentaria y de autoorganización, la tributaria y financiera, la de programación o planificación, la expropiatoria y de investigación, deslinde y recuperación de oficio de sus bienes, la presunción de legitimidad y la ejecutividad de sus actos, la de ejecución forzosa y sancionadora, la de revisión de oficio de sus actos y acuerdos, las prelaciones y preferencias y demás prerrogativas reconocidas a la Hacienda Pública para los créditos de las mismas, la inembargabilidad de sus bienes y derechos en los términos previstos en las leyes.

${ }^{50}$ Concretamente, Ordenación del Territorio y Urbanismo, Sanidad, Servicios Sociales, Cultura y Deporte, Salubridad pública y medio ambiente, Turismo y tradiciones populares, Artesanía, Agricultura, Ganadería y Montes, Minería, Ferias y mercados comarcales, Energía y promoción industrial.
} 
ámbito comarcal y de Asistencia y cooperación técnica, jurídica y económica a los municipios ${ }^{51}$ (art. 9. 1 LCB).

El Gobierno y la Administración de la Comarca corresponde al Consejo Comarcal (art. 10 LCB), cuyos órganos son el Pleno, el Presidente y la Comisión de Gobierno (art. $11 \mathrm{LCB})^{52}$. El régimen de funcionamiento y el procedimiento de adopción de acuerdos de estos órganos es el establecido en la legislación de régimen local (art. 24 LCB).

El Pleno Comarcal es el órgano representativo de los Ayuntamientos, y está integrado por un número de miembros en representación de cada uno de ellos (art. $12 \mathrm{LCB})^{53}$. Sus atribuciones las recoge el artículo $21 \mathrm{LCB}^{54}$, pudiendo delegar algunas de éstas en la Comisión de Gobierno ${ }^{55}$.

\footnotetext{
${ }^{51}$ La adopción de los acuerdos para hacer efectiva la delegación o transferencia corresponde al Pleno de la Diputación Provincial y requiere, en todo caso, previo acuerdo favorable del Consejo Comarcal El Bierzo.
}

${ }^{52} \mathrm{El}$ art. 18 LCB permite al Pleno complementar esta organización mediante acuerdo plenario o mediante la aprobación del correspondiente Reglamento Orgánico Comarcal. A lo que el art. 19 LCB añade la posibilidad, si las necesidades funcionales de la Comarca lo aconsejan, de nombrar un gerente, que sea responsable de la gestión técnica y de la administración comarcal, bajo la superior autoridad del Presidente. Para acordar dicho nombramiento se requiere el voto favorable de los dos tercios del número de miembros que integran el Pleno. Siendo un cargo incompatible con el de miembro del Pleno Comarcal, al que le serán de aplicación las mismas incompatibilidades establecidas para los miembros de la Corporación. Tendrá la condición de personal eventual, cesando automáticamente cuando expire el mandato del pleno que lo designó. A ello añade el art. 25 LCB que en el «Consejo Comarcal existirá un puesto de trabajo denominado Secretaría, cuya clase se determinará por el Ministerio para las Administraciones Públicas, y al que corresponde la responsabilidad administrativa de las funciones de fe pública y el asesoramiento legal preceptivo». «Cuando el Ministerio para las Administraciones Públicas clasifique en la primera o en la segunda clase al puesto de trabajo referido en el número anterior, también existirán los puestos de trabajo denominados Intervención y Tesorería, que tendrán atribuida la responsabilidad administrativa de las funciones de control y fiscalización interna de la gestión económica-financiera y presupuestario el primero y la contabilidad, tesorería y recaudación el segundo».

${ }^{53}$ Concretamente, se deben seguir las siguientes reglas para determinar el número de miembros de cada Ayuntamiento: a) los municipios cuyo número de residentes no exceda de 5.000 estarán representados por un concejal; b) los municipios cuyo número de residentes esté comprendido entre 5.001 y 50.000, estarán representados por tres concejales; c) Ponferrada estará representada por siete concejales (art. 12. 1 LCB). La determinación del número de concejales que por cada uno de los Ayuntamientos hayan de representar a éstos en el Consejo se hará por la Junta Electoral Provincial (art. 12. 2 LCB).

${ }^{54}$ Concretamente: a) aceptar o denegar la incorporación de nuevos municipios a la Comarca; b) el control y la fiscalización de los órganos de gobierno; c) la aprobación del Reglamento Orgánico y de las Ordenanzas; d) elegir al Presidente del Consejo y a la Comisión de Gobierno; e) aceptar o denegar las transferencias y delegaciones de competencias hechas por otras Administraciones Públicas; f) la aprobación de los Planes Comarcales; g) la determinación de los recursos propios de carácter tributario; h) la aprobación y modificación de los Presupuestos y la aprobación de las cuentas; i) la aprobación de la relación de puestos de trabajo; la fijación de la cuantía de las retribuciones complementarias de los funcionarios y del número y régimen del personal eventual; y la ratificación del despido del personal laboral; j) el ejercicio de las acciones administrativas y judiciales; k) la aprobación de las formas de gestión de los servicios y de los expedientes a que se refiere el art. 86. 1 LBRL; 1) la alteración de la calificación jurídica de los bienes de dominio público; $\mathrm{m}$ ) la enajenación del patrimonio; $\mathrm{n}$ ) el planteamiento de conflictos de competencia a otras Entidades Locales y demás Administraciones Públicas; o) ejercer las demás atribuciones que expresamente le asignan las leyes y aquellas que la legislación asigna a la Comarca y no atribuya a otros órganos comarcales; p) la votación sobre la moción de censura al Presidente (art. 21 LCB).

${ }_{55}$ Más concretamente, podrá delegar únicamente las contenidas en las letras h, i, 1 y m del listado recogido en el apartado anterior. 
El Presidente será elegido en la sesión constitutiva del Pleno del Consejo Comarcal (art. 16. 1 LCB), en una primera votación por mayoría absoluta, y de no conseguirse ésta en segunda votación por mayoría simple. En caso de empate se repite la votación, y en caso de que el empate persista, se elegirá al candidato del partido, coalición, federación o agrupación de electores que hubiese obtenido mayor número de votos en la Comarca (art. 16. 2 LCB). Sus atribuciones aparecen recogidas en el art. $20 \mathrm{LCB}^{56}$, pudiendo delegar la mayor parte de sus atribuciones en la Comisión de Gobierno (art. 20. 2 LCB) ${ }^{57}$.

La Comisión de Gobierno está integrada por el Presidente y un número de miembros del Pleno no superior al tercio de los que integran éste (art. 17. 1 LCB). La determinación del número de miembros y su elección corresponde al Pleno, pero respetando en proporción la importancia numérica que los grupos políticos tengan en el pleno (art. 17. 2 LCB). A este órgano corresponden la asistencia al Presidente en el ejercicio de sus atribuciones y las atribuciones delegadas por otros órganos de la Comarca (art. 22 LCB).

En cualquier caso, no parece previsible hoy en día, que los planteamientos del actual Gobierno de la Comunidad se dediquen a primar las comarcas, sino que más bien parecen dirigirse hacia la potenciación de las áreas metropolitanas y mancomunidades.

\subsection{Mancomunidades}

Según el art. 29 LRLCyL, son Mancomunidades de Municipios «las asociaciones que éstos formen voluntariamente para la ejecución en común de obras y servicios determinados de su competencia», cuyo ámbito de actuación no podrá extenderse a la totalidad de las competencias asignadas a los propios municipios que las integran. Tienen la condición de Entidad Local, personalidad y capacidad jurídica para el cumplimiento de sus fines específicos y se rigen por el régimen jurídico recogido en sus Estatutos.

Pueden ostentar, en el ámbito de sus competencias, las potestades y prerrogativas que recoge el art. 4. 1 LBRL, si bien los acuerdos que adopten en materia de expropiación forzosa deberán ser autorizados por la Junta de Castilla y León (art. 30 LRLCyL).

\footnotetext{
${ }^{56}$ Concretamente: a) la dirección del gobierno y la administración comarcales; b) representar al Consejo Comarcal; c) convocar y presidir las sesiones del Pleno y la de los demás órganos colegiados; d) nombrar y cesar libremente, de entre los miembros de la Comisión de Gobierno, a los Vicepresidentes cuyo número no podrá ser superior a tres; e) ejercer la jefatura superior del personal; f) dirigir, inspeccionar e impulsar los servicios y obras comarcales; g) supervisar las obras comarcales y los servicios de la Administración de la Comarca; h) ejercitar las acciones judiciales y administrativas en caso de urgencia; i) ordenar la publicación de los acuerdos de los órganos colegiados que la exijan; j) ejercer las facultades de contratación en los términos previstos en el art. 21 LBRL; k) las que las leyes le atribuyan o le delegue el Pleno del Consejo Comarcal (art. 20. 1 LCB).

57 Concretamente, podrá delegar todas, salvo las contenidas en las letras c), d) y g) del listado recogido en la nota anterior (art. 20. 2 LCB).
} 
La Ley fija la figura de la Mancomunidad de interés comunitario, que serán aquéllas cuyo ámbito territorial concuerde sustancialmente con espacios de ordenación territorial para la prestación de servicios estatales, autonómicos o provinciales. Contando las que reciban dicha calificación con algunos beneficios especiales, como una línea específica y preferente de financiación o la posibilidad de solicitar su institucionalización como comarca (art. 32 LRLCyL).

La iniciativa para la creación de mancomunidades corresponde a cada uno de los municipios que la asuman mediante acuerdo de los Plenos de sus Ayuntamientos, en los que se designará a los miembros que representarán a la Corporación en la Comisión Promotora ${ }^{58}$, que será quien elaborará el anteproyecto de Estatutos y se encargará de la tramitación del procedimiento hasta la constitución de los órganos de gobierno de la Comunidad (art. 33 LRLCyL).

La elaboración del proyecto de Estatutos corresponde a una Asamblea integrada por todos los concejales de los ayuntamiento interesados ${ }^{59}$, que para su válida constitución deberá contar con la presencia de la mayoría de esos concejales y, en todo caso, de los que formasen la Comisión Promotora, y la del Presidente y Secretario de ésta, que actuarán como Presidente y Secretario de la citada Asamblea (art. 34 LRLCyL).

El proyecto elaborado será sometido a información pública por el plazo de un mes, a informe de la Diputación Provincial o Diputaciones Provinciales interesadas y de la Consejería competente en materia de Administración Local. Todo ello se remitirá al presidente de la Comisión Promotora para su aprobación por las Corporaciones interesadas por mayoría absoluta del número legal de sus miembros. Tras lo cual será remitida una copia del Expediente y de los Estatutos de la Mancomunidad a la Consejería competente en materia de Administración Local, para su inscripción en el Registro de Entidades Locales y su publicación en el BOCYL, momento a partir del cual será efectiva su constitución de la que se dará traslado a la Administración del Estado (art. 36 y 36 LRLCyL).

La modificación y supresión de la Mancomunidad y la modificación de sus Estatutos se remite al procedimiento fijado en los propios Estatutos de ésta, si bien con respeto a las reglas que recogen los art. 38 y sigs. LRLCyL (art. 37 LRLCyL) ${ }^{60}$.

\footnotetext{
58 Será Presidente de esa Comisión Promotora el que de entre sus miembros éstos elijan y actuará como Secretario el que lo sea del Ayuntamiento al que pertenezca el Presidente (art. 33. 2 LRLCyL).

$59 \mathrm{Si}$ hay municipios que funcionen en régimen de concejo abierto, serán convocados el Alcalde y los Tenientes de Alcalde, si los hubiere (art. 34. 1 LRLCyL).

${ }^{60}$ La modificación de los Estatutos está regulada en el art. 37 LRLCyL, que atribuye la iniciativa para dicha modificación a los municipios mancomunados o al órgano de gobierno de la mancomunidad, requiriendo en todo caso acuerdo de éste. Tras información pública e informe la Diputación Provincial o de las Diputaciones Provinciales interesadas y de la Conserjería competente en materia de Administra-
} 


\subsection{Otras entidades asociativas}

El art. 42 LRLCyL reconoce las Comunidades de Villa y Tierra, Comunidades de Tierra, Asocios y otras entidades asociativas tradicionales que existan en la Comunidad de Castilla y León, que ostentarán personalidad y capacidad jurídica para el cumplimiento de sus fines. Se regirán por sus normas consuetudinarias o tradicionales, ajustando su régimen en cuanto a la formación de presupuestos, rendición de cuentas, liquidaciones e inventarios a la normativa vigente para las Entidades Locales. La modificación de sus Reglamentos o Estatutos se llevará a cabo de acuerdo con los procedimientos en ellos establecidos o, en su defecto, según costumbre, o a falta de ésta, según lo establecido para la modificación y supresión de mancomunidades (art. 42 y 43 LRLCyL).

También hace referencia la Ley a las Entidades Metropolitanas, señalando que aquellos municipios entre cuyos núcleos de población existan vinculaciones económicas, sociales y urbanas que hagan necesaria una actuación de alcance supramunicipal, se podrán integrar en una Entidad Metropolitana para la planificación conjunta y la gestión conjunta de determinadas obras y servicios (art. 45. 1 LRLCyL).

Su creación, modificación o supresión se llevará a cabo por una Ley específica para cada supuesto ${ }^{61}$, previa audiencia de la Administración del Estado y de los Ayuntamientos y Diputaciones Provinciales interesadas. La iniciativa puede partir de los municipios interesados, requiriéndose en tal caso acuerdo adoptado por mayoría absoluta de los miembros legales de la Corporación (art. 45. 2 y 45. 3 LRLCyL).

Estas Entidades tendrán la condición de Entidad Local, personalidad jurídica propia y plena capacidad para el ejercicio de sus competencias. La Ley

ción Local, la aprobación definitiva corresponderá a todos los Ayuntamientos de los municipios mancomunados, mediante acuerdo adoptado por mayoría absoluta del número legal de sus miembros, cuando se trate de una modificación sustancial de los Estatutos. Si no es una modificación sustancial, basta con el pronunciamiento favorable de dos tercios de los Ayuntamientos de los municipios mancomunados, mediante acuerdo adoptado por mayoría absoluta de sus miembros legales. El art. 39 regula la adhesión o separación de municipios, requiere en todo caso información pública e informe de la Diputación o Diputaciones Provinciales interesadas y de la Consejería competente en materia de Administración Local. Además de aprobación del órgano de gobierno de la Mancomunidad, cuando se trate de una adhesión. La adhesión o separación modificará automáticamente los Estatutos, sin necesidad de seguir el procedimiento recogido en el artículo anterior. La supresión de mancomunidades se sujetará, según el art. 40 LRLCyL, al régimen establecido en el art. 38 LRLCyL. La mancomunidad mantendrá su personalidad jurídica hasta que el órgano de gobierno apruebe la liquidación y distribución de su patrimonio, mediante acuerdo que se publicará en el BOCYL.

${ }^{61}$ La Ley por la que se cree una Entidad Metropolitana debe contener al menos las determinaciones siguientes: a) las potestades y prerrogativas de las que está investida; b) los órganos de gobierno y administración, en los que estarán representados todos los Ayuntamientos; c) el régimen económico y de funcionamiento, que garantizará la participación de todos los municipios en la toma de decisiones y una justa distribución de las cargas entre ellos; d) las obras y servicios de realización o prestación metropolitana y el procedimiento para su ejecución (art. 47 LRLCyL). 
prevé, además, la existencia de un Consejo en el que estarán representados todos los municipios integrados, para decidir sobre los servicios de interés común (art. 45 y 46 LRLCyL).

Por último, la Ley hace referencia a la posibilidad de que las Entidades Locales constituyan consorcios con cualquier otra Administración pública o entidad privada sin ánimo de lucro que persiga fines de interés público concurrentes con los de las Administraciones Públicas, para la realización de actuaciones conjuntas, la coordinación de actividades y la consecución de fines de interés común. Esos consorcios tienen personalidad jurídica propia y se regirán por lo establecido en sus Estatutos (art. 48 LRLCyL).

\section{ENTIDADES LOCALES MENORES}

Se entiende por tales aquellas entidades de ámbito inferior al municipio que bajo diversas denominaciones tienen reconocido dicho carácter o las que se creen de acuerdo a lo establecido en la LRLCyL. Tienen la consideración de Entidad Local, personalidad y capacidad jurídica plena para el ejercicio de sus competencias (art. 49 LRLCyL).

Tienen las competencias recogidas en el art. $50 \mathrm{LRLCyL}^{62}$, para cuyo ejercicio podrán ostentar las potestades que regula el art. $51 \mathrm{LRLCyL}^{63}$.

Se podrán constituir como tales aquellos núcleos de población que, en el término municipal, estén separados de aquél donde radique la capitalidad, en los casos que establece el art. 52. 1 LRLCyL ${ }^{64}$, debiendo, en todo caso, reunir los requisitos que establece el art. 52. 2 LRLCyL. Si bien en ningún caso podrá constituirse como tal la capitalidad del municipio ni las urbanizaciones de iniciativa particular. Tampoco podrán existir Entidades Locales Menores que pertenezcan a dos o más municipios (art. 53 LRLCyL).

\footnotetext{
${ }^{62}$ Concretamente: a) la administración y conservación de su patrimonio, incluido el forestal, y la regulación del aprovechamiento de sus bienes comunales; b) la vigilancia, conservación y limpieza de vías urbanas, caminos rurales, fuentes, lavaderos y abrevaderos; c) la ejecución de las obras y prestación de los servicios que le delegue expresamente el Ayuntamiento (art. 50 LRLCyL).

${ }^{63}$ Concretamente: a) la potestad reglamentaria y de autoorganización; b) el establecimiento de tasas, precios públicos y contribuciones especiales; c) la potestad de programación o planificación; d) la potestad de investigación, deslinde y recuperación de oficio de sus bienes; e) la presunción de legitimidad y la ejecutividad de sus actos; f) la potestad de ejecución forzosa y sancionadora; g) la potestad de revisión de oficio de sus actos y acuerdos; h) la inembargabilidad de sus bienes y derechos en los términos previstos en las leyes; las prelaciones y preferencias y demás prerrogativas reconocidas a la Hacienda Pública para los créditos de la misma, sin perjuicio de los que correspondan a las Haciendas del Estado, de la Comunidad Autónoma y de los municipios; i) cuando ejerciten competencias por delegación del municipio ostentarán en relación con éstas, además, la potestad expropiatoria (art. 51 LRLCyL).

${ }^{64}$ Concretamente: a) cuando se suprima el municipio al que pertenezcan; b) cuando por alteración de los términos municipales pasen dichos núcleos a formar parte de otros municipios; c) cuando lo soliciten los vecinos residentes en el núcleo o el municipio al que el mismo pertenezca (art. 52 y 54 LRLCyL).
} 
Sus órganos de gobierno serán los Alcaldes Pedáneos, elegidos directamente por los vecinos, y la Junta Vecinal, que estará integrada por el Alcalde Pedáneo, que la preside, y por dos o cuatro vocales, según el núcleo sea inferior o no a 250 residentes (art. 57 LRLCyL).

Su supresión se podrá producir porque dejen de reunir los requisitos requeridos para su existencia o por la concurrencia de los supuestos del art. 71. 2 LRLCyL ${ }^{65}$, a iniciativa de los sujetos a los que hace referencia el art. 71. 3 LRLCyL ${ }^{66}$.

\section{LA DIFÍCIL PROBLEMÁTICA DEL CONDADO DE TREVIÑO}

Uno de los temas que, sin duda, más discusiones ha generado en la Administración Local de nuestra Comunidad es la ubicación en nuestra Comunidad Autónoma del Condado de Treviño, enclave histórico de la provincia de Burgos, que está ubicado, sin embargo, dentro de los límites geográficos del País Vasco.

Este factor ha enfrentado a Castilla y León con la Comunidad Vasca, que ha pretendido desde hace ya tiempo la incorporación de dicho enclave geográfico a su territorio. Para ello se introdujo una regulación que preveía la incorporación del Condado al País Vasco. Dicha regulación chocaba frontalmente, sin embargo, con la normativa castellano leonesa, que también se refirió a esa cuestión. Concretamente en la Disposición Transitoria Séptima del Estatuto, según el cual para «que un territorio o municipio que constituya un enclave perteneciente a una provincia integrada en la Comunidad Autónoma de Castilla y León pueda segregarse de la misma e incorporarse a otra Comunidad Autónoma será necesario el cumplimiento de los siguientes requisitos:

a) Solicitud de segregación, formulada por el Ayuntamiento o Ayuntamientos interesados, mediante acuerdo adoptado con el voto favorable de las dos terceras partes del número de hecho y, en todo caso, de la mayoría absoluta de los miembros de dicha o dichas Corporaciones.

b) Informe de la provincia a la que pertenezca el territorio o municipio a segregar y de la Comunidad Autónoma de Castilla y León, favorable a tal

\footnotetext{
${ }^{65}$ Concretamente: a) incumplimiento continuado y manifiesto de las competencias que detenten; b) cuando celebradas elecciones locales, hubiesen quedado reiteradamente sin cubrir los órganos rectores de la Entidad por falta de candidaturas; c) cuando se aprecien notorios motivos de necesidad económica o administrativa; d) cuando así lo solicite la mayoría de los vecinos (art. 71. 2 LRLCyL).

${ }^{66}$ Concretamente: a) a quienes la tienen para su creación; b) a la Junta Vecinal mediante acuerdo adoptado por la mayoría absoluta de los miembros que la forman; c) a la Consejería competente en materia de Administración Local. El procedimiento será el mismo que el establecido para su constitución, debiendo darse audiencia a todas las partes interesadas (art. 71 LRLCyL).
} 
segregación, a la vista de las mayores vinculaciones históricas, sociales, culturales y económicas con la Comunidad Autónoma a la que se solicite la incorporación. A tal efecto, la Comunidad Autónoma de Castilla y León podrá realizar encuestas y otras formas de consulta con objeto de llegar a una más motivada resolución.

c) Refrendo entre los habitantes del territorio o municipio que pretende la segregación, aprobado por mayoría de los votos válidos emitidos.

d) Aprobación por las Cortes Generales, mediante Ley Orgánica.

En todo caso, el resultado de este proceso quedará pendiente del cumplimiento de los requisitos de agregación exigidos por el Estatuto de la Comunidad Autónoma a la que se pretende la incorporación».

Como es lógico, la normativa castellana preveía un proceso complejo y difícil de llevar a la práctica, en la que la llave de la decisión final estaba en mano de la Comunidad Castellana. Regulación que, como era previsible, no gustó al País Vasco, que veía en ella una vulneración de su propio estatuto, que había regulado previamente dicha cuestión, en forma bastante más flexible.

La cuestión acabó llegando al Tribunal Constitucional, que dio la razón, como era previsible, a nuestra Comunidad. El Interprete Máximo de nuestra Norma Básica salvó la superioridad de ésta respecto a los Estatutos de Autonomía, indicando que el conflicto se debía resolver en el marco de la Constitución, y no en base a una imposible preeminencia de un Estatuto sobre otro, que se basase en el dato puramente contingente del momento de su aprobación. Desde esta perspectiva, resultaba evidente que un Estatuto no puede regular unilateralmente el procedimiento de segregación de un territorio perteneciente a otra Comunidad Autónoma, sino que debe limitarse a reglar «el proceso de formación y manifestación de la voluntad de cada una de ellas para perfeccionar - mediante actos distintos, pero complementarios- el complejo procedimiento en que consiste la segregación de un enclave y su agregación a otra Comunidad» ${ }^{67}$.

Si bien contra esta decisión Leguina ViLLA formuló un importante voto particular en contra, en el que señalaba que «la colisión normativa existe efectivamente y que no me parece posible salvarla con la invocación de un presunto "derecho" de cada Comunidad Autónoma a regular este aspecto del problema desde su propia óptica y como mejor le parezca. Por ello, no siendo posible la aplicación simultánea de los preceptos estatutarios al supuesto planteado por el enclave de Treviño debería haberse estimado los recursos de inconstitucionalidad promovidos por el Gobierno y el Parlamento Vasco».

A pesar de estos argumentos la decisión nos parece, como ya hemos adelantado, de una coherencia lógica incuestionable. Aunque esto no la salvó de

${ }^{67}$ STC 99/1986, de 11 de julio de 1986. FJ. 6. 
la discusión y la polémica, pues no fue ésta pacíficamente recibida, enfrentando a la doctrina, que asumió posiciones muy divergentes al respecto. Así, algunos alabaron sus virtudes ${ }^{68}$, mientras que otros vieron en ella una doctrina injustificada y criticable. No nos parecen justificadas dichas críticas, si bien, sin cuestionar el fondo de la cuestión, entendemos cierto que en todo el desarrollo de la cuestión, como apunta certeramente SÁNCHEZ BLANCO, ha habido un cierto olvido de los intereses de los ciudadanos implicados, para centrar la cuestión en una estéril disputa de límites territoriales ${ }^{69}$.

\section{EL PACTO LOCAL. LA SEGUNDA DESCENTRALIZACIÓN ADMINISTRATIVA}

El pacto local nacional se concretó, como ha señalado SÁNCHEZ DE VEGA, en 1999, mediante una serie de medidas que vinieron a fortalecer las competencias y poderes locales. Pero esto dejaba aún pendiente el Segundo Pacto Local o segunda descentralización administrativa, a través de la que se debía producir el traspaso de esas competencias desde la Administración autonómica a las Administraciones locales ${ }^{70}$.

La plasmación legal del Pacto Local constituye, como indica el propio texto del mismo, «un deber constitucional, el que se impone a las Comunidades Autónomas de potenciar la autonomía y la máxima intervención posible de las Entidades Locales en los asuntos que afecten directamente al círculo de sus intereses territoriales propios, y que deriva del principio general de la descentralización recogido en el art. 103. 1 del texto de la Constitución». Si bien eso no impide que sea un «deber que tiene un alcance práctico y concreto constitucionalmente indeterminado, correspondiendo al legislador estatal o autonómico la concreción del contenido de la autonomía local».

Con el mismo se pretende, como fin último, el acercamiento de la Administración al ciudadano y la proximidad como garantía de una eficaz gestión de los servicios públicos ${ }^{71}$. Concretándose, para lograr dicho fin en un con-

\footnotetext{
${ }^{68}$ Rivero Ysern, E., Comentarios al Estatuto de Autonomía de la Comunidad Autónoma de Castilla y León (obra de la que el mismo es coordinador). Madrid, 1985. Págs. 335-336. DíEz PiCAZO, L. N., «Sobre la delimitación estatutaria del territorio de las Comunidades Autónomas y la rigidez de los Estatutos», en Revista Española de Derecho Constitucional 20 (1987), pp. 139-176.

${ }^{69}$ SÁnchez Blanco, A., «Ajustes territoriales en las Comunidades Autónomas. Derechos institucionales y derechos de las Comunidades sociales. La sentencia del Tribunal Constitucional 99/1986 relativa al Condado de Treviño», en Revista Vasca de Administración Pública 16 (1986), pp. 131 y 154.

70 SÁnchez de Vega, A., «La segunda descentralización», en Jornadas sobre «El Poder Local», Facultad de Derecho de La Coruña.

${ }^{71}$ El texto del pacto concreta en mayor medida esos objetivos, señalando los siguientes: a) el acercamiento de la Administración al ciudadano, con el objetivo de que la Administración Pública que en cada caso ejerce las competencias o presta los servicios que afectan directamente al ciudadano sea la más cercana, la más eficaz y la que más participación le permite; b) fortalecimiento de las instancias locales ayudando así a reafirmar la identidad regional, con el propósito de contribuir a definir la estruc-
} 
junto de compromisos políticos tendentes a su cumplimiento. Si bien, detrás de ellos, se proclama la existencia de algo más: «una voluntad política, una forma de comportarse los poderes públicos, y como tal, un proceso constante y evolutivo».

De esta forma, el Pacto Local aparece definido como «un proceso dinámico para la creación de un nuevo marco de relaciones entre la Comunidad Autónoma y las Corporaciones Locales y el refuerzo de los poderes locales, a través del desarrollo de un conjunto de medidas, complementarias entre sí, de naturaleza jurídica y política que se establecen como instrumentos al servicio de una sociedad cada vez más dinámica y exigente».

Para dar satisfacción al mismo se articulan una serie de medidas, que se concretan, con carácter general en los siguientes puntos:

1. Medidas de refuerzo competencial, para incrementar y potenciar las facultades de gestión de las Corporaciones Locales de cara al ciudadano, y clarificar la distribución de competencias entre la Administración de la Comunidad Autónoma y las Entidades Locales.

2. Medidas de cooperación institucional, para analizar el grado de participación de las Entidades Locales en los órganos colegiados de la Administración Regional.

3. Medidas de vertebración administrativa, que persiguen el diseño de los distintos tipos de Entidades Locales y su funcionalidad.

4. Medidas de cooperación económica, para fijar un marco económico estable que garantice el desarrollo de la autonomía de las Entidades Locales para el ejercicio de sus competencias.

tura administrativa de nuestro territorio en un proceso de innegable repercusión en la ordenación territorial de los Entes Locales de Castilla y León; c) adecuación de la vertebración administrativa mediante la integración y cohesión del territorio, profundizando en la descentralización y en el reparto de poder; d) fomentar una mayor cooperación institucional, habilitando instrumentos para la participación de las Corporaciones Locales en importantes ámbitos de decisión que afectan a sus intereses. 